\title{
Corneal densitometry in different stages of keratoconus
}

\author{
Authors: Mohammed B. Ahsounah, Waleed A. Abou-Samra, Mohamad Khalaf, Rania K. Farag \\ Mansoura Ophthalmic Center, Mansoura University, Mansoura, Egypt.
}

Corresponding author: Mohammed B. Ahsounah, Mansoura Ophthalmic Center, Mansoura University, Mansoura, Egypt. Email: aghaamohammed@gmail.com

Received: 14-3-2021, Accepted: 24-5-2021, Published online:10-6-2021

EJO(MOC) 2021;1:91-102.

Short title: Corneal densitometry in different stages of keratoconus

\begin{abstract}
Purpose: The aim of this study was to evaluate corneal clarity in keratoconic patients using corneal densitometry.

Methods: comparing between corneal densitometry results among keratoconic patients and normal individual was measured over a $12 \mathrm{~mm}$ diameter area, divided the cornea to annular concentric zones and depths. Keratoconus was classified according to the topographic keratoconus classification, from March 2019 to March 2020 in Ophthalmic center Mansoura University, Egypt.

Results: Group 1: 20 eyes diagnosed as manifest grade 1 keratoconus; Group 2: 20 eyes diagnosed as manifest grade 2 keratoconus; Group 3: 20 eyes diagnosed as manifest grade 3 keratoconus; Group 4: 20 eyes diagnosed as manifest grade 4 keratoconus; with 40 eyes normal topographic parameter a control group. There was a significant difference between keratoconous patients and control group regarding UCVA, BCVA, spherical refraction, cylindrical refraction and Pentacam parameters all ( $\mathbf{P}<\mathbf{0 . 0 5}$ ). The study comparison between the studied groups regarding anterior (120 $\mathrm{mm}$ ), central (from $120 \mathrm{~mm}$ to the last $60 \mathrm{~mm}$ ) and posterior (last $60 \mathrm{~mm}$ ) layers measurements showed increase in corneal densitometry reading in 0-2 $\mathrm{mm}, 2-6 \mathrm{~mm}, 6-10 \mathrm{~mm}, 10-12 \mathrm{~mm}$ anular zones in keratoconous patient and compared to control group, there was significantly increased in densitometry readings in keratoconous eyes and was related to keratoconous severity all $(\mathbf{P}<\mathbf{0 . 0 5})$.
\end{abstract}

Conclusions: The densitometry readings increase in keratoconic eyes with higher values with increasing severity of keratoconus. So it is valuable diagnostic tool for diagnosting \& following up the progression of the disease it represent data as corneal densitometry backscatter.

Kay - Words: Keratoconous, light backscatter, Corneal densitometry.

\section{INTRODUCTION:}

Keratoconus $(\mathrm{KC})$ is non-inflammatory disease with anatomic deformity of the cornea characterized by progressive conical protrusion and thinning of the corneal center part. ${ }^{1} \quad$ Keratoconus is the most common corneal ecstatic disorder. Patients with KC suffer from a significant visual impairment, which in advanced cases can only be restored by corneal transplantation surgery. $\mathrm{KC}$ is a complex disorder attributed to different contributors including genetics and environmental factors. ${ }^{2}$ Corneal densitometry, as an indicator for corneal health, has many applications in corneal diagnosis, ${ }^{3,4}$ This is by quantitative measurement of

Egyptian Journal of Ophthalmology, a publication of Mansoura Ophthalmic Center.

Address: Mansoura Ophthalmic Center, Mansoura University, Mansoura, Egypt.

Website: https://ejomos.journals.ekb.eg

Tel. 0020502202064 Fax. 0020502202060.

E-mail: ejo@mans.edu.eg 
the corneal clarity. The Pentacam HR (Oculus, Wetzlar, Germany) includes a densitometry analysis software system, which measures backscattered light intensity from the different regions of the cornea. ${ }^{5}$ Values of anterior densitometry are derived from the anterior $120 \mu \mathrm{m}(0.120$ $\mathrm{mm}$ ) of the corneas, central densitometry derived from central cornea, and posterior densitometry derived from the posterior $60 \mu \mathrm{m}(0.60 \mathrm{~mm})$ of the cornea. ${ }^{6}$ Healthy cornea does not absorb visible light, and the dispersal of light is minimal. Therefore, densitometry can provide a measurement of the level of the corneal transparency. ${ }^{7}$ Disruption of the corneal collagen matrix during oedema and the resultant corneal scarring can provoke an increase in corneal light scatterin, ${ }^{\mathbf{8}, 9}$ so several disease as corneal infiltrates, corneal deposits and corneal ecstatic lead to increase light backscattering. ${ }^{10,11}$ keratoconus produces several changes in the cornea. These changes disturbance the distribution of corneal extracellular matrix and cells and lead to the increase of scatter. ${ }^{12}$ Corneal densitometry assesses the amount of backscattered light in the form of density units called gray scale units, if no detectable backscatter, the reported density will be zero with the top end to the scale being 100, also can assess the corneal thickness at the same locations of backscattered light, ${ }^{13}$ an increased densitometry being a predictable consequence of the development of discrete opacities in the corneal stroma. ${ }^{14}$
This study aimed to evaluate corneal densitometry changes in keratoconus stages and to compare these results with those of healthy individuals.

\section{PATIENTS AND METHODS:}

Inclusion and exclusion criteria:

This study included eighty keratoconic eyes of patients divided into four sub groups in comparison to forty normal eyes using Pentacam oculus Scheimpflug photography system from March 2019 to march 2020 in Ophthalmic center Mansoura University Egypt. The studied subjects were subdivided according to ABCD grading system ${ }^{\mathbf{1 5}}$ shown as in (Fig. 1). Patients with keratoconus aged between 15 to 40 years old, both sexes, Diagnosed clinically by slit lamp in outpatient clinic, and based on different indices driven from the Pentacam topographic maps with reliable quality of scan (ok). Normal subjects with Age between 15 to 40 years old Both sex No keratoconic changes by clinical examination in outpatient clinic and No Pentacam changes with reliable quality of scan (QS, ok). Exclusion of history of cross linking, Posterior segment disorders, Any pathological condition affecting corneal clarity as corneal opacities, dystrophies \& corneal hydrops, Retinal and Optic nerve diseases, Collagen diseases, diabetes mellitus or hormonal changes (such as pregnancy), History of any previous refractive, or ocular surgery and History of any ocular injuries. 


\begin{tabular}{|c|c|c|c|c|c|}
\hline ABCD Criteria & A & B & C & D & \\
\hline & $\begin{array}{c}\text { ARC } \\
\text { (3 mm zone) }\end{array}$ & $\begin{array}{c}\text { PRC } \\
\text { (3 mm zone) }\end{array}$ & $\begin{array}{l}\text { Thinnest } \\
\text { Pach um }\end{array}$ & BDVA & Scarring \\
\hline STAGE 0 & $\begin{array}{l}>7.25 \mathrm{~mm} \\
(<46.5 \mathrm{D})\end{array}$ & $\begin{array}{l}>5.90 \mathrm{~mm} \\
(<57.25 \mathrm{D})\end{array}$ & $>490$ um & $\begin{array}{l}220 / 20 \\
(21,0)\end{array}$ & - \\
\hline STAGE I & $\begin{array}{l}>7.05 \mathrm{~mm} \\
\text { (<48.0 D) }\end{array}$ & $\begin{array}{l}>5.70 \mathrm{~mm} \\
\text { (<59.25 D) }\end{array}$ & $>450$ um & $\begin{array}{l}<20 / 20 \\
(<1,0)\end{array}$ &,,-+++ \\
\hline STAGE II & $\begin{array}{l}>6.35 \mathrm{~mm} \\
(<53.0 \mathrm{D})\end{array}$ & $\begin{array}{l}>5.15 \mathrm{~mm} \\
(<65.5 \mathrm{D})\end{array}$ & $>400$ um & $\begin{array}{l}<20 / 40 \\
(<0.5)\end{array}$ &,,-+++ \\
\hline STAGE III & $\begin{array}{l}>6.15 \mathrm{~mm} \\
(<55.0 \mathrm{D})\end{array}$ & $\begin{array}{l}>4.95 \mathrm{~mm} \\
(<68.5 \mathrm{D})\end{array}$ & $>300$ um & $\begin{array}{c}<20 / 100 \\
\quad<0.2)\end{array}$ &,,-+++ \\
\hline STAGE IV & $\begin{array}{l}<6.15 \mathrm{~mm} \\
(>55.0 \mathrm{D})\end{array}$ & $\begin{array}{l}<4.95 \mathrm{~mm} \\
(>68.5 \mathrm{D})\end{array}$ & s 300 um & $\begin{array}{l}<20 / 400 \\
k 0.05)\end{array}$ &,,-+++ \\
\hline
\end{tabular}

Fig. (1): ABCD grading system of keratoconus by Ambrósio

\begin{abstract}
Methodology
The following were done for all studied cases including general ophthalmic history following with ophthalmic examination including, visual acuity measurement using Landolt's broken ring chart then transformed to Log mar, Manifest refractions using the auto-refractometer, Evaluation of BCVA, Slit lamp bio microscopy for corneal examination and dilated fundus examination to exclude any posterior segment disorder.
\end{abstract}

\section{Corneal densitometry tomography.}

All eyes examined using oculus pentacam scheimpflug topography (Pentacam HR, Oculus GMbH, Wetzlar, Germany) was used to confirm the diagnosis of corneal topographic parameters for $\mathrm{KC}$ classification then detect corneal densitometry. The participant was asked to place his/her chin on the chin rest and press his/her forehead against the forehead strap. The participant's eye was aligned to the visual axis with a central fixation target. After proper alignment and blinking a few times, the automatic release mode, with 25 single Scheimpflug images, was started for each eye. Only cases with acceptable image quality were included in the final analysis. A single trained operator performed all examinations. All parameters were automatically calculated by the Pentacam software (Version 1.20r36). An internal standard corneal densitometry analysis software measures the backscattered light over a $12-\mathrm{mm}$ diameter corneal area, zonal corneal densitometry values were automatically measured in 4 concentric annular zones (0-2 mm, 2-6 mm, 6-10 mm, 10-12 mm, total diameter) and by depth (anterior layer: inner $120 \mu \mathrm{m}$; center layer: from $120 \mu \mathrm{m}$ to the last $60 \mu \mathrm{m}$; posterior layer: last $60 \mu \mathrm{m}$ ) with estimation of density clarity as a topical graphical map (Cornea densitometry Average) and set of numbers in (gray scale units) for different locations on cornea surface over 12 mm. (Fig. 2). 


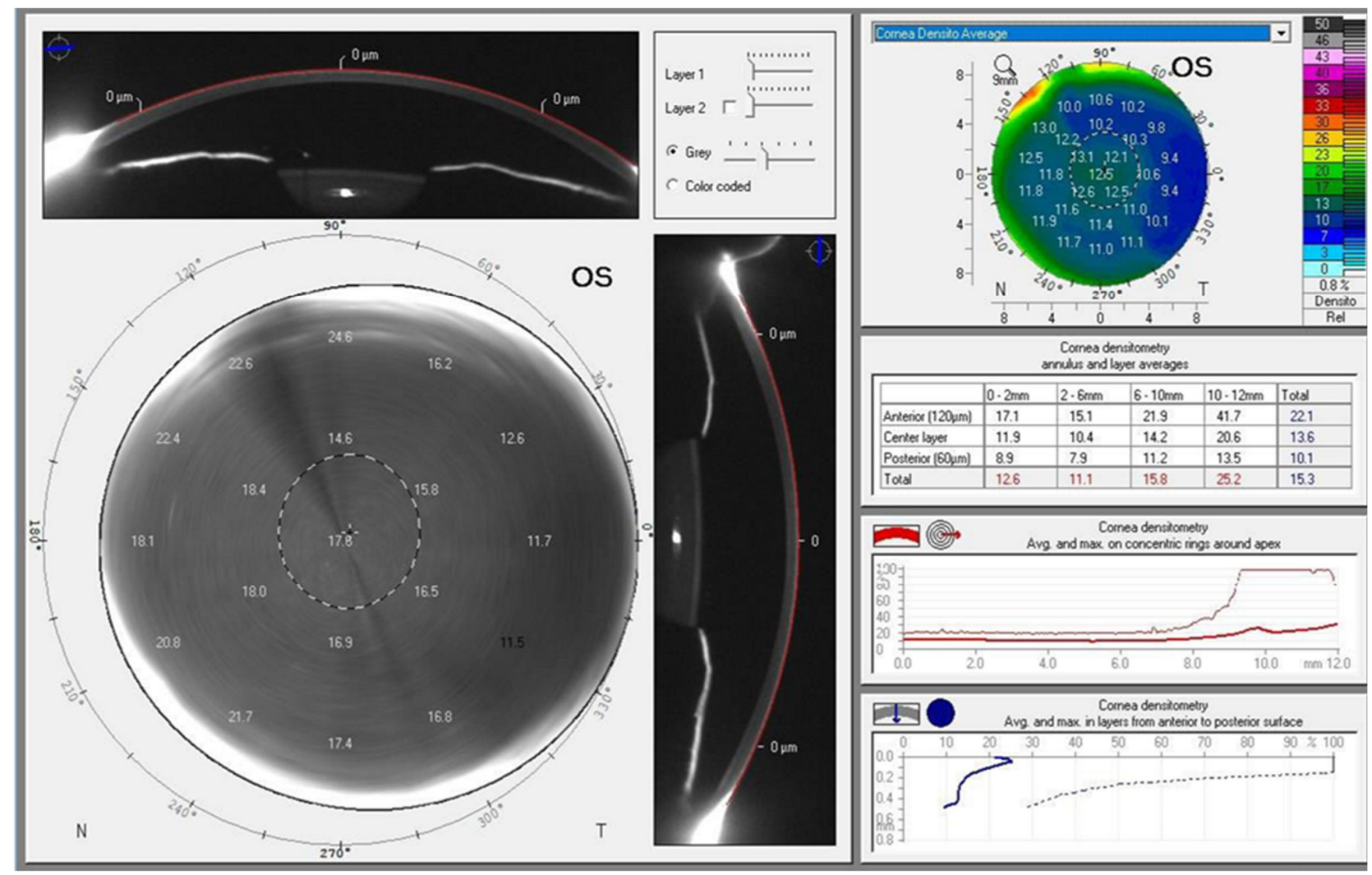

Fig. (2): corneal densitometry image display by (Mansoura ophthalmology center).

\section{STATISTICAL ANALYSIS:}

Patients were first divided into 5 groups: Normal and four grades of Keratoconus disease. Data were fed to the computer and analyzed using IBM SPSS software package version 20.0. The groups were compared with F-test (ANOVA) to compare between more than two groups, Student $t$ test for parametric data and Mann Whitney test for non-parametric data. Receiver operating characteristic (ROC) curves were plotted. Area under the ROC curve was calculated to describe the predictive accuracy of the different indices and to determine the cut off point for the most sensitive parameters. Pearson (parametric) and Spearman (non-parametric) correlation were used to correlate continuous data. Level of significance for all above mentioned statistical tests done, the threshold of significance is fixed at 5\% level (p-value).

\section{RESULTS:}

This cross-sectional observational study included 80 eyes of 80 patients with keratoconus divided into 4 grades according to the severity of keratoconus and the results were compared to 40 eyes from age and sex matched subjects as controls group. Keratoconous patients included 42 males $(52.5 \%)$ and 38 females (47.5\%) with an age of $29.5 \pm 6.4$ years. Patients were divided into 4 equal groups according to keratoconus severity. There was a significant difference between keratoconous patients and control group regarding UCVA, BCVA, spherical refraction, cylindrical refraction and Pentacam parameters all $(\mathbf{P}<\mathbf{0 . 0 5})$. There was densitometry comparison between the studied groups regarding anterior layer measurements in 0-2 $\mathrm{mm}, 2-6 \mathrm{~mm}$, 6-10 mm, 10-12 $\mathrm{mm}$ zones in keratoconous patients compared to control group, showed increase in corneal densitometry parameters in keratoconus patients compared to control group and this increase was in direct proportion 
with severity of keratoconus are shown in the table (1) all (P $<\mathbf{0 . 0 5}$ ) (Fig. 2). Also Comparison between the studied groups regarding central layer measurements in 0-2 mm, 2-6 mm, 6$10 \mathrm{~mm}, 10-12 \mathrm{~mm}$ zones in keratoconous patient compared to control group showed increase in corneal densitometry parameters in keratoconus patients compared to control group and this increase was in direct proportion with severity of keratoconus are shown in the following table (2) all (P $<\mathbf{0 . 0 5}$ ) (Fig. 2). Also comparison between the studied groups regarding posterior layer measurements in $0-2 \mathrm{~mm}, 2-6 \mathrm{~mm}$, 6-10 mm, 10-12 mm zones in keratoconous patient compared to control group showed increase in corneal densitometry parameters in keratoconus patients compared to control group and this increase was in direct proportion with severity of keratoconus are shown in the following table (3) all (P $<\mathbf{0 . 0 5}$ ) (Fig. 3). And Comparison between the studied groups regarding total layer measurements in 0-2 mm, 2-6 mm, 6$10 \mathrm{~mm}, 10-12 \mathrm{~mm}$ zones in keratoconous patient compared to control group showed increase in corneal densitometry parameters in keratoconus patients compared to control group and this increase was in direct proportion with severity of keratoconus are shown in the following table (4) all (P $<\mathbf{0 . 0 5})$ (Fig.3)

Table-1 Comparison between the studied groups regarding anterior layer measurements

\begin{tabular}{|c|c|c|c|c|c|c|c|}
\hline $\begin{array}{l}\text { Annular } \\
\text { zones }\end{array}$ & $\begin{array}{l}\text { All patients } \\
\qquad \mathbf{N}=\mathbf{1 2 0}\end{array}$ & $\begin{array}{l}\text { Ke } 1 \\
\mathbf{N}=\mathbf{2 0}\end{array}$ & $\begin{array}{l}\text { Ke } 2 \\
N=20\end{array}$ & $\begin{array}{l}\text { Ke } 3 \\
N=20\end{array}$ & $\begin{array}{l}\text { Ke } 4 \\
N=20\end{array}$ & $\begin{array}{c}\text { Controls } \\
\text { N=40 }\end{array}$ & $\mathbf{P}$ \\
\hline 0-2mm & $26.3 \pm 7.8$ & $21.7 \pm 1.5$ & $24.2 \pm 3.5$ & $25.0 \pm 1.6$ & $33.9 \pm 12.2$ & $21.4 \pm 1.6$ & 0.001 \\
\hline $2-6 \mathrm{~mm}$ & $20.5 \pm 4.3$ & $18.8 \pm 1.3$ & $19.9 \pm 1.6$ & $21.4 \pm 1.5$ & $21.9 \pm 8.0$ & $18.9 \pm 1.4$ & 0.001 \\
\hline 6-10mm & $19.6 \pm 5.0$ & $18.6 \pm 3.1$ & $19.8 \pm 4.3$ & $19.9 \pm 4.6$ & $19.6 \pm 7.5$ & $18.4 \pm 2.6$ & 0.001 \\
\hline $10-12 \mathrm{~mm}$ & $32.1 \pm 11.1$ & $30.3 \pm 4.3$ & $34.3 \pm 10.2$ & $34.5 \pm 12.9$ & $26.7 \pm 13.2$ & $28.7 \pm 6.7$ & 0.001 \\
\hline Total & $23.0 \pm 4.3$ & $21.1 \pm 1.7$ & $22.9 \pm 3.1$ & $23.3 \pm 3.7$ & $24.0 \pm 7.0$ & $20.8 \pm 1.8$ & 0.001 \\
\hline \multicolumn{8}{|c|}{$\mathrm{KC}$ keratoconus } \\
\hline \multicolumn{8}{|c|}{ P: probability. } \\
\hline \multicolumn{8}{|c|}{ Categorical data expressed as Number $(\%)$} \\
\hline \multicolumn{8}{|c|}{ Quantitative data are expressed as mean $\pm \mathrm{SD}$} \\
\hline P stati & lly significan & $\leq 0.05)$ & & & & & \\
\hline
\end{tabular}


Table-2 Comparison between the studied groups regarding central layer measurements

\begin{tabular}{|c|c|c|c|c|c|c|c|}
\hline $\begin{array}{l}\text { Annular } \\
\text { zones }\end{array}$ & $\begin{array}{l}\text { All patients } \\
\qquad \mathbf{N}=\mathbf{1 2 0}\end{array}$ & $\begin{array}{l}\text { Ke } 1 \\
N=\mathbf{2 0}\end{array}$ & $\begin{array}{l}\text { Ke } 2 \\
N=\mathbf{2 0}\end{array}$ & $\begin{array}{l}\text { Ke } 3 \\
\mathbf{N}=\mathbf{2 0}\end{array}$ & $\begin{array}{l}\text { Ke } 4 \\
N=20\end{array}$ & $\begin{array}{l}\text { Controls } \\
\qquad \mathbf{N}=40\end{array}$ & $\mathbf{P}$ \\
\hline 0-2mm & $16.1 \pm 5.5$ & $13.6 \pm 0.8$ & $14.6 \pm 1.6$ & $14.6 \pm 0.9$ & $21.4 \pm 9.1$ & $13.4 \pm 0.9$ & 0.001 \\
\hline $2-6 \mathrm{~mm}$ & $12.8 \pm 3.7$ & $11.9 \pm 0.6$ & $12.4 \pm 1.2$ & $12.7 \pm 1.5$ & $13.9 \pm 7.0$ & $11.9 \pm 0.7$ & 0.001 \\
\hline 6-10mm & $13.2 \pm 3.6$ & $12.2 \pm 1.7$ & $13.0 \pm 2.4$ & $13.3 \pm 3.0$ & $13.9 \pm 6.1$ & $12.1 \pm 1.6$ & 0.001 \\
\hline $\mathbf{1 0 - 1 2 m m ~}$ & $19.6 \pm 6.3$ & $18.0 \pm 2.7$ & $20.1 \pm 4.6$ & $20.7 \pm 7.1$ & $18.0 \pm 8.8$ & $17.8 \pm 3.3$ & 0.001 \\
\hline Total & $14.6 \pm 3.3$ & $13.3 \pm 1.0$ & $14.2 \pm 1.7$ & $14.4 \pm 2.3$ & $15.9 \pm 5.8$ & $13.2 \pm 0.9$ & 0.001 \\
\hline \multicolumn{8}{|c|}{ KC keratoconus } \\
\hline \multicolumn{8}{|c|}{ P: probability. } \\
\hline \multicolumn{8}{|c|}{ Categorical data expressed as Number $(\%)$} \\
\hline \multicolumn{8}{|c|}{ Quantitative data are expressed as mean $\pm \mathrm{SD}$} \\
\hline \multicolumn{8}{|c|}{ P statistically significant $(\mathrm{P} \leq 0.05)$} \\
\hline \multicolumn{8}{|c|}{ Table-3 Comparison between the studied groups regarding posterior layer measurements } \\
\hline Annular & All patients & Ke 1 & Ke 2 & Ke 3 & Ke 4 & Controls & $\mathbf{P}$ \\
\hline zones & $\mathbf{N}=120$ & $\mathbf{N}=\mathbf{2 0}$ & $\mathbf{N}=\mathbf{2 0}$ & $\mathbf{N}=\mathbf{2 0}$ & $\mathbf{N}=\mathbf{2 0}$ & $\mathbf{N}=\mathbf{4 0}$ & \\
\hline 0-2mm & $10.7 \pm 3.0$ & $10.1 \pm 0.7$ & $10.2 \pm 1.4$ & $9.3 \pm 1.2$ & $13.1 \pm 5.1$ & $10.3 \pm 0.8$ & 0.001 \\
\hline $2-6 \mathrm{~mm}$ & $10.2 \pm 1.8$ & $9.2 \pm 0.5$ & $10.0 \pm 0.7$ & $10.5 \pm 0.8$ & $11.0 \pm 3.2$ & $9.3 \pm 0.6$ & 0.001 \\
\hline 6-10mm & $10.7 \pm 2.2$ & $9.9 \pm 1.1$ & $10.5 \pm 1.8$ & $10.6 \pm 2.2$ & $11.1 \pm 3.3$ & $9.9 \pm 1.2$ & 0.001 \\
\hline 10-12mm & $14.7 \pm 4.5$ & $13.4 \pm 2.4$ & $14.6 \pm 3.0$ & $16.0 \pm 4.5$ & $13.6 \pm 6.5$ & $12.6 \pm 1.9$ & 0.001 \\
\hline Total & $11.1 \pm 1.8$ & $10.3 \pm 0.8$ & $11.0 \pm 1.2$ & $11.1 \pm 1.5$ & $11.8 \pm 2.9$ & $10.2 \pm 0.7$ & 0.001 \\
\hline
\end{tabular}

KC keratoconus

P: probability.

Categorical data expressed as Number (\%)

Quantitative data are expressed as mean \pm SD

$\mathrm{P}$ statistically significant $(\mathrm{P} \leq 0.05)$ 
Table-4 Comparison between the studied groups regarding total measurements

\begin{tabular}{|c|c|c|c|c|c|c|c|}
\hline $\begin{array}{l}\text { Annular } \\
\text { zones }\end{array}$ & $\begin{array}{l}\text { All patients } \\
\qquad N=120\end{array}$ & $\begin{array}{l}\text { Ke } 1 \\
N=\mathbf{2 0}\end{array}$ & $\begin{array}{l}\text { Ke } 2 \\
N=\mathbf{2 0}\end{array}$ & $\begin{array}{l}\text { Ke } 3 \\
N=20\end{array}$ & $\begin{array}{l}\text { Ke } 4 \\
N=20\end{array}$ & $\begin{array}{l}\text { Controls } \\
\qquad \mathbf{N}=40\end{array}$ & $\mathbf{P}$ \\
\hline 0-2mm & $17.7 \pm 5.1$ & $15.1 \pm 0.8$ & $16.3 \pm 1.8$ & $16.3 \pm 1.0$ & $22.8 \pm 8.0$ & $15.0 \pm 0.9$ & 0.001 \\
\hline $2-6 \mathrm{~mm}$ & $14.5 \pm 3.2$ & $13.3 \pm 0.7$ & $14.1 \pm 1.1$ & $14.9 \pm 1.2$ & $15.6 \pm 6.0$ & $13.4 \pm 0.8$ & 0.001 \\
\hline 6-10mm & $14.5 \pm 3.5$ & $13.6 \pm 1.9$ & $14.4 \pm 2.8$ & $14.6 \pm 3.2$ & $14.9 \pm 5.5$ & $13.5 \pm 1.7$ & 0.001 \\
\hline $10-12 \mathrm{~mm}$ & $22.2 \pm 6.9$ & $20.6 \pm 2.6$ & $23.0 \pm 5.6$ & $23.9 \pm 7.7$ & $19.4 \pm 9.4$ & $19.7 \pm 3.7$ & 0.001 \\
\hline Total & $16.2 \pm 3.0$ & $14.9 \pm 1.1$ & $16.0 \pm 2.0$ & $16.3 \pm 2.4$ & $17.2 \pm 5.1$ & $14.7 \pm 1.0$ & 0.001 \\
\hline
\end{tabular}

\section{KC keratoconus}

P: probability.

Categorical data expressed as Number (\%)

Quantitative data are expressed as mean \pm SD

$\mathrm{P}$ statistically significant $(\mathrm{P} \leq 0.05)$

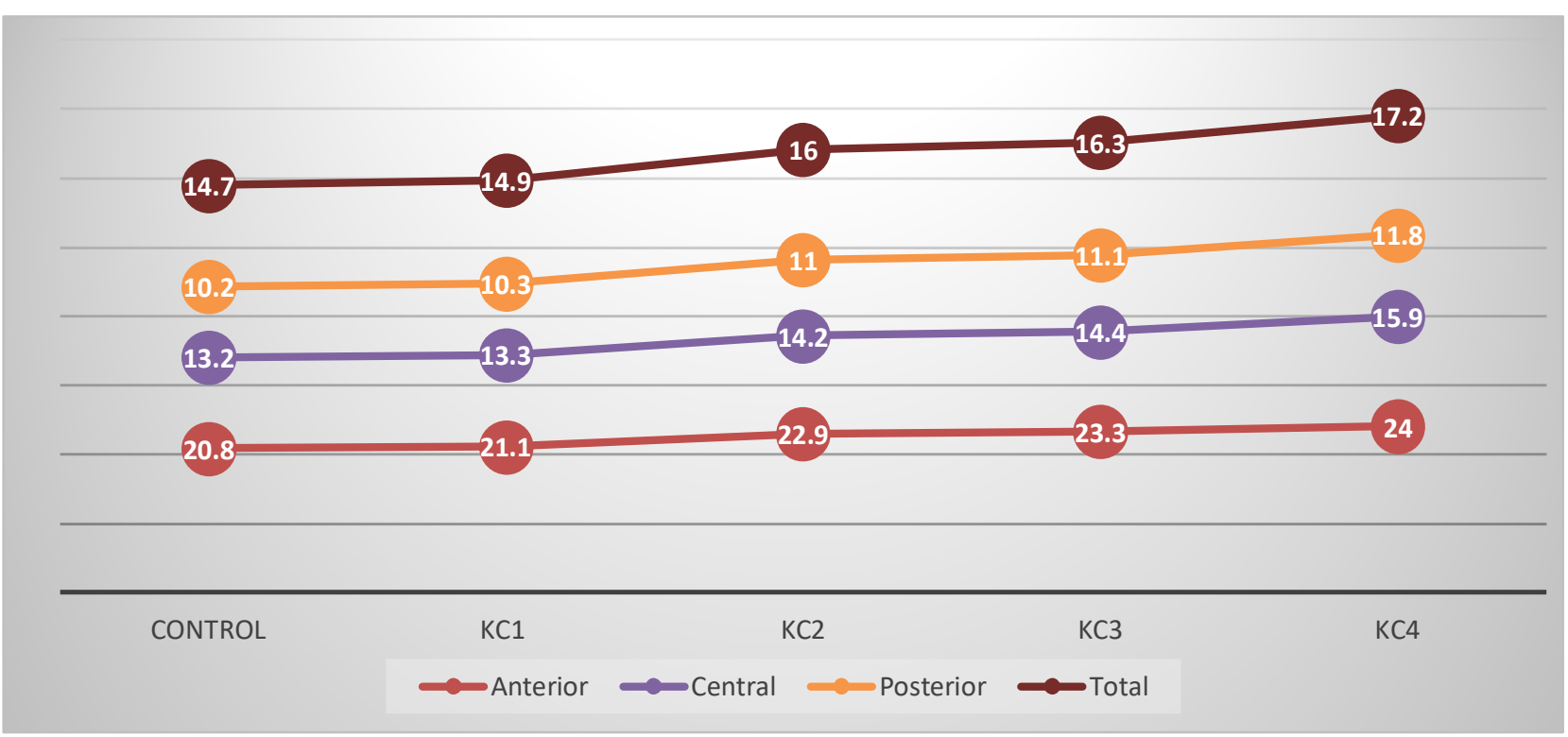

Fig. (3) Anterior, central, posterior and total of studied layers

Diagnostic performance and cut-off point for total densitometry in $\mathrm{KC} 1, \mathrm{KC} 2, \mathrm{KC} 3$ and $\mathrm{KC} 4$ patients from controls are shown in the following tables (Tables5-8). 
Table-5 Value of total densitometry in distinguishing KC1 from controls

\begin{tabular}{lc}
\hline Cut-off & $\mathbf{1 4 . 9}$ \\
\hline AUC & 0.54 \\
$\mathbf{P}$ & 0.001 \\
Sensitivity & $55.0 \%$ \\
Specificity & $50.0 \%$ \\
\hline AUC area under curve & P statistically significant $(\mathrm{P} \leq 0.05)$ \\
Table-6 Value of total densitometry in distinguishing KC2 from controls
\end{tabular}

\begin{tabular}{lc}
\hline Cut-off & $\mathbf{1 6}$ \\
\hline AUC & 0.7 \\
\hline P & 0.002 \\
Sensitivity & $65.0 \%$ \\
Specificity & $80.0 \%$ \\
\hline AUC area under curve & P statistically significant $(\mathrm{P} \leq 0.05)$ \\
\hline
\end{tabular}

Table-7 Value of total densitometry in distinguishing KC3 from controls

\begin{tabular}{lc}
\hline Cut-off & $\mathbf{1 6 . 3}$ \\
\hline AUC & 0.71 \\
$\mathbf{P}$ & 0.001 \\
Sensitivity & $65.0 \%$ \\
Specificity & $80.0 \%$ \\
\hline AUC area under curve & P statistically significant $(\mathrm{P} \leq 0.05)$ \\
\hline
\end{tabular}

Table-8 Value of total densitometry in distinguishing KC4 from controls

\begin{tabular}{lc}
\hline Cut-off & $\mathbf{1 7 . 2}$ \\
\hline AUC & 0.77 \\
\hline P & 0.003 \\
Sensitivity & $80.0 \%$ \\
Specificity & $80.0 \%$ \\
\hline AUC area under curve & P statistically significant $(\mathrm{P} \leq 0.05)$ \\
\hline
\end{tabular}

Densitometry correlation between total corneal pentacam parameters of (CCT, ART MAX) and there densitometry in $(\mathrm{KC} 1, \mathrm{KC} 2, \mathrm{KC} 3, \mathrm{KC} 4)$ with pentacam was a statistically significant positive correlation parameters of (K MAX, ART MAX, CCT) There was a between corneal densitometry in (KC1, KC2, KC3, KC4 statistically significant negative correlation between ) and K MAX values as shown in the following table (9) corneal densitometry in ( $\mathrm{KC} 1, \mathrm{KC} 2, \mathrm{KC} 3, \mathrm{KC} 4)$ with and figure (4). 
Table-9 Correlation between total corneal densitometry and other parameters.

\begin{tabular}{llcccc}
\hline & & $\begin{array}{c}\text { KC1 } \\
\text { DENSITO }\end{array}$ & $\begin{array}{c}\text { KC2 } \\
\text { DENSITO }\end{array}$ & $\begin{array}{c}\text { KC3 } \\
\text { DENSITO }\end{array}$ & $\begin{array}{c}\text { KC4 } \\
\text { DENSITO }\end{array}$ \\
\hline K max & r & 0.264 & 0.008 & 0.077 & 0.088 \\
& P & 0.017 & 0.021 & 0.061 & 0.043 \\
CCT & r & -0.043 & -0.063 & -0.077 & -0.114 \\
& $\mathrm{P}$ & 0.046 & 0.038 & 0.047 & 0.033 \\
& $\mathrm{r}$ & -0.039 & -0.045 & -0.070 & -0.150 \\
& $\mathrm{P}$ & 0.033 & 0.036 & 0.042 & 0.046 \\
\hline
\end{tabular}

KC keratoconus $\quad \mathrm{r}$ : Spearman ${ }^{e e}$ s correlation $\quad \mathrm{p}$ : probability significant $(\mathrm{p} \leq 0.05)$
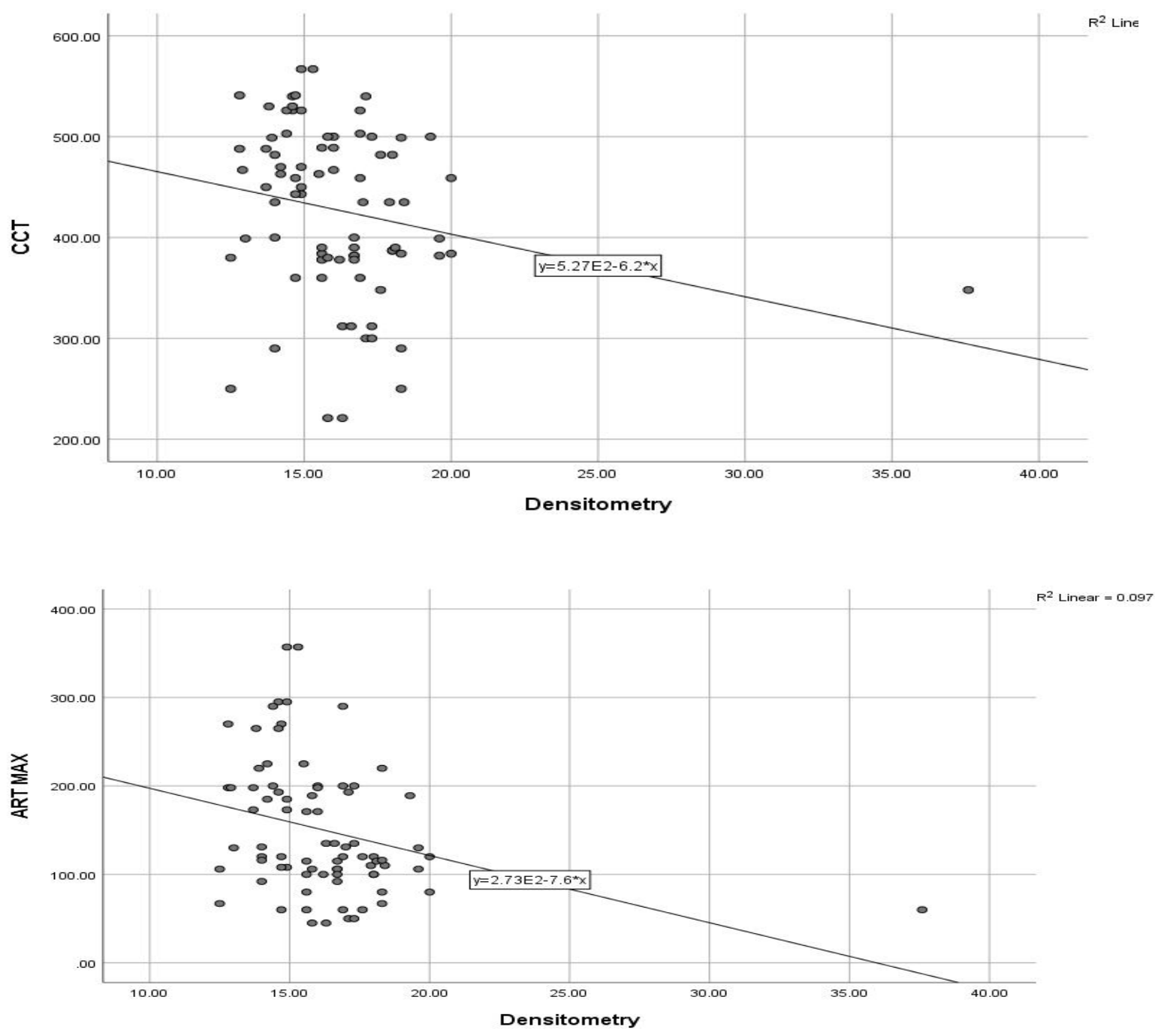


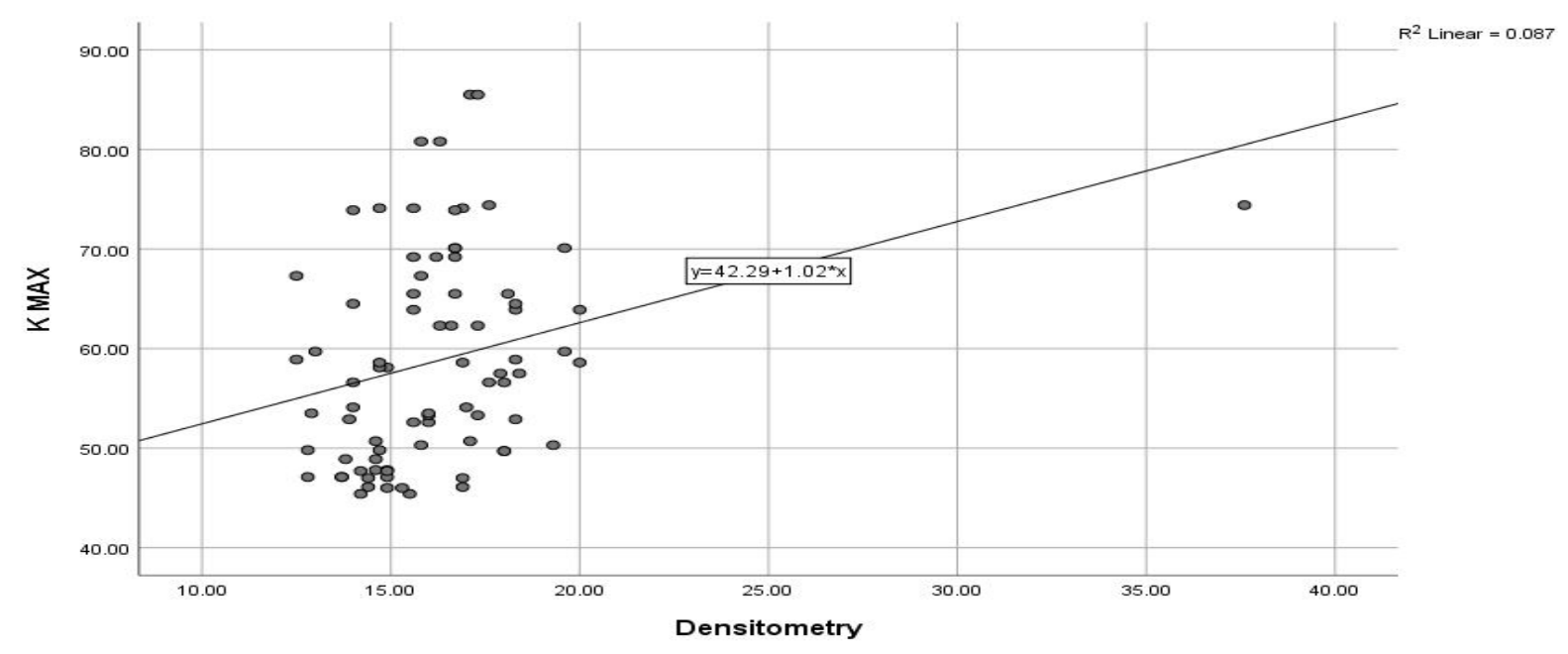

Fig. (4) Corneal densitometry keratoconus correlation with pentacam parameters group

\section{DISCUSSION:}

Keratoconus is non-inflammatory disease with anatomic deformity of the cornea characterized by progressive conical protrusion and thinning of the corneal center part. ${ }^{16}$ Early diagnosis of keratoconus is currently a diagnostic challenge as there is no uniform screening criteria so early diagnosis help to stop progression and better management. ${ }^{17}$ Corneal densitometry nowadays is a valuable tool for evaluation of corneal transparency. ${ }^{18}$ Present study aimed to evaluate the corneal densitometry findings in patients with $\mathrm{KC}$, This cross sectional study included 80 eyes of 80 patients with keratoconous divided into 4 grades according to the severity of keratoconous and compared to 40 eyes of healthy control with matching age and sex. The studied patients included 42 males $(52.5 \%)$ and 38 females $(47.5 \%)$ indicating almost equal sex distribution.

In the present study, comparison between the studied groups regarding anterior, central, posterior, and total layers measurements, and also regarding to the annular zones (0-2 mm, 2-6 mm , 6-10 mm , 10-12 mm) showed increase in corneal densitometry parameters in keratoconus patients compared to control group and this increase was in direct proportion with severity of keratoconus, This is matching with Lopes et al. $(2014)^{19}$ who showed increase in densitometry readings in keratoconic patients, but did not correlate this readings with grades of keratocous. Also Shen et al. (2019) ${ }^{20}$ showed the correlation between corneal densitometry, corneal topographic parameters, and corneal biomechanical properties in keratoconus. Corneal densitometry and topography were measured using Pentacam. The corneal densitometry values of the anterior 0 to 2 and 2 to $6 \mathrm{~mm}$ layers significantly correlated with the severity of keratoconus. In addition Kreps et al. $(2020)^{21}$ showed that corneal densitometry in keratoconic patients regarding anterior layer measurements, central layer measurements, posterior layer measurements and total layer measurements significantly worse compared to controls. Most parameters worsened in moderate disease and severe disease.

The present study showed different cut-off values for densitometry in different keratoconus stages correlate with sensitivity and specificity. Cut-off point was 14.9 in $\mathrm{KC} 1$, 16.0 in $\mathrm{KC} 2,16.3$ in $\mathrm{KC} 3$, and 17.2 in $\mathrm{KC} 4$.

\section{CONCLUSION:}

Corneal densitometry is corneal profiling technique which is highly sensitive for detection of keratoconous, it is valuable 
diagnostic tool for diagnosing \& following up the progression of the disease it represent data as corneal densitometry backscatter. There is no single diagnostic index to diagnosis of keratoconus, so with combination of several data raising the diagnostic of keratoconus early, and help in avoiding misdiagnosis of keratoconus. From these results we have new cut off values for corneal densitometry in keratoconic patients and also for every stages, and also in management plane of keratoconus, these values may be helpful in diagnosis and detection of keratoconus.

Consent for publication: Not applicable.

Availability of data and materials: All the data supporting our findings is contained within the manuscript.

Competing interests: The authors declare that there is no conflict of interest in the current research work.

Funding: This research did not receive any specific grant from funding agencies in the public, commercial or not for profit sectors.

\section{REFERENCES:}

1. Sanchis-Gimeno, J.A., Herrera, M., Rahhal, M.S., Martínez-Soriano, F., 2020. Effect of contact lens wear on the anatomic values of the corneal thickness. European Journal of Anatomy 11, 181-184.

2. Khaled, M.L., Liu, Y. 2020. Genetics of keratoconus, In: Genetics and Genomics of Eye Disease. Elsevier, 219235.

3. Lopes, B., Ramos, I., Ambrósio Jr, R., 2014a. Corneal densitometry in keratoconus. Cornea 33, 1282-1286.

4. Otri, A.M., Fares, U., Al-Aqaba, M.A., Dua, H.S., 2012. Corneal densitometry as an indicator of corneal health. Ophthalmology 119, 501-508.

5. Piñero, D. P. (2015). Technologies for anatomical and geometric characterization of the corneal structure and anterior segment: a review. Semin Ophthalmol, 30(3), 161-170. doi:10.3109/08820538.2013.835844

6. Doughty, M. J., \& Zaman, M. L. J. S. o. o. (2000). Human corneal thickness and its impact on intraocular pressure measures: a review and meta-analysis approach. 44(5), 367-408.

7. Otri, A.M., Fares, U., Al-Aqaba, M.A., Dua, H.S., 2012. Corneal densitometry as an indicator of corneal health. Ophthalmology 119, 501-508.

8. Baratz, K.H., McLaren, J.W., Maguire, L.J., Patel, S.V., 2012. Corneal haze determined by confocal microscopy 2 years after Descemet stripping with endothelial keratoplasty for Fuchs corneal dystrophy. J Archives of ophthalmology 130, 868-874.

9. Tekin, K., Sekeroglu, M.A., Kiziltoprak, H., Yilmazbas, P.J., 2017. Corneal densitometry in healthy corneas and its correlation with endothelial morphometry. Cornea 36, 1336-1342.

10. Enders, P., Holtick, U., Schaub, F., Tuchscherer, A., Hermann, M.M., Scheid, C., Cursiefen, C., Bachmann, B.O.J., 2016. Corneal densitometry for quantification of corneal deposits in monoclonal gammopathies. Cornea $36,470-475$.

11. Lopes, B., Ramos, I., Ambrósio Jr, R.J.C., 2014b. Corneal densitometry in keratoconus. 33, 1282-1286.

12. Rabinowitz, Y.S., Dong, L., Wistow, G.J.I.o., science, v., 2005. Gene expression profile studies of human keratoconus cornea for NEIBank: a novel corneaexpressed gene and the absence of transcripts for aquaporin 5. 46, 1239-1246.

13. Dhubhghaill, S.N., Rozema, J.J., Jongenelen, S., Hidalgo, I.R., Zakaria, N., Tassignon, M.-J., 2014a. Normative values for corneal densitometry analysis by Scheimpflug optical assessment. Investigative ophthalmology \& visual science 55, 162-168.

14. Pekel, G., Özbakış, F., Bahar, A., Pekel, E., \& Çetin, E. N. (2018). Correlations of Corneal Optical Densitometry, Endothelial Hexagonality Percentage, and Epithelium Thickness. Curr Eye Res, 43(2), 170-174. doi:10.1080/02713683.2017.1387271 
15. Ambrósio, R., Caiado, A. L. C., Guerra, F. P., Louzada, R., Roy, A. S., Luz, A., . . Belin, M. W. J. J. o. r. s. (2011). Novel pachymetric parameters based on corneal tomography for diagnosing keratoconus. 27(10), 753-758.

16. Sanchis-Gimeno, J.A., Herrera, M., Rahhal, M.S., Martínez-Soriano, F., 2020. Effect of contact lens wear on the anatomic values of the corneal thickness. European Journal of Anatomy 11, 181-184.

17. Zhang, M., Zhang, F., Li, Y., Song, Y., Wang, Z., 2020. Early Diagnosis of Keratoconus in Chinese Myopic Eyes by Combining Corvis ST with Pentacam. Current Eye Research 45, 118-123.

18. Dhubhghaill, S.N., Rozema, J.J., Jongenelen, S., Hidalgo, I.R., Zakaria, N., Tassignon, M.-J.J.I.o., science, v., 2014b. Normative values for corneal densitometry analysis by Scheimpflug optical assessment. 55, 162-168.

19. Lopes, B., Ramos, I., Ambrósio Jr, R.J.C., 2014b. Corneal densitometry in keratoconus. 33, 1282-1286.

20. Shen, Y., Han, T., Jhanji, V., Shang, J., Zhao, J., Li, M., Zhou, X., 2019. Correlation between corneal topographic, densitometry, and biomechanical parameters in keratoconus eyes. Translational vision science \& technology 8, 12-12.

21. Kreps, E.O., Jimenez-Garcia, M., Issarti, I., Claerhout, I., Koppen, C., Rozema, J.J., 2020. Repeatability of the Pentacam HR in Various Grades of Keratoconus. American journal of ophthalmology 219, 154-162. 